NBER WORKING PAPER SERIES

\title{
PUBLIC DEBT, FISCAL SOLVENCY AND MACROECONOMIC UNCERTAINTY IN LATIN AMERICA: THE CASES OF BRAZIL, COLOMBIA, COSTA RICA AND MEXICO
}

\author{
Enrique G. Mendoza \\ P. Marcelo Oviedo \\ Working Paper 10637 \\ http://www.nber.org/papers/w10637
NATIONAL BUREAU OF ECONOMIC RESEARCH 1050 Massachusetts Avenue
Cambridge, MA 02138
July 2004

This paper was prepared for the World Bank's project on Assessing Fiscal Sustainability in Latin America and is based on a method to evaluate fiscal sustainability that we developed while visiting the Research Department of the Inter-American Development Bank. We are grateful to Manuel Amador, Andres Arias, Guillermo Calvo, Umberto Della Mea, Arturo Galindo, Santiago Herrera, Claudio Irigoyen, Alejandro Izquierdo, Guillermo Perry, Tom Sargent, Alejandro Werner and participants at the XIX Meeting of the Latin American Network of Central Banks and Finance Ministries for helpful comments and suggestions. The views expressed here are the authors' only and do not reflect those of the World Bank or the Inter-American Development Bank. The views expressed herein are those of the author(s) and not necessarily those of the National Bureau of Economic Research.

(C)2004 by Enrique G. Mendoza and P. Marcelo Oviedo. All rights reserved. Short sections of text, not to exceed two paragraphs, may be quoted without explicit permission provided that full credit, including (C) notice, is given to the source. 
Public Debt, Fiscal Solvency and Macroeconomic Uncertainty in Latin America: The Cases of Brazil, Colombia, Costa Rica, and Mexico

Enrique G. Mendoza and P. Marcelo Oviedo

NBER Working Paper No. 10637

July 2004

JEL No. F0, F4

\section{$\underline{\text { ABSTRACT }}$}

Ratios of public debt as a share of GDP in Brazil, Colombia, and Mexico were 10 percentage points higher on average during 1996-2002 than in the period 1990-1995. Costa Rica's debt ratio remained stable but at a high level near 50 percent. Is there reason to be concerned for the solvency of the public sector in these economies? We provide an answer to this question based on the quantitative predictions of a variant of the framework proposed by Mendoza and Oviedo (2004). This methodology yields forward-looking estimates of debt ratios consistent with fiscal solvency for a government that faces revenue uncertainty and can issue only non-state-contingent debt. In this environment, aversion to a collapse in outlays leads the government to respect a "natural debt limit" equal to the annuity value of the primary balance in a "fiscal crisis." A fiscal crisis occurs after a long sequence of adverse revenue shocks and public outlays adjust to a tolerable minimum. The debt limit also represents a credible commitment to be able to repay even in a fiscal crisis but is not, in general, the same as the sustainable debt, which is driven by the probabilistic dynamics of the primary balance. The results of a baseline scenario question the sustainability of current debt ratios in Brazil and Colombia, while those in Costa Rica and Mexico seem inside the limits consistent with fiscal solvency. In contrast, public debt ratios are found to be unsustainable in all four countries for plausible changes to lower average growth rates or higher real interest rates. Moreover, sustainable debt ratios fall sharply when default risk is taken into account.

Enrique G. Mendoza Department of Economics University of Maryland College Park, MD 20742 and NBER mendozae@econ.umd.edu
Pedro Marcelo Oviedo

Department of Economics

Iowa State University

Ames, IA 50011

oviedo@iastate.edu 


\section{Introduction}

The ratios of public debt to GDP have been rising steadily in the economies of Latin America. Comparing averages for the period 1996-2002 with those for the period 1990-1995, the average debt ratios of Brazil, Colombia, and Mexico increased by about 10 percentage points in each country. In Costa Rica, the public debt ratio did not change much, but it was already at a relatively high level of around 50 percent at the beginning of the 1990s. Given that growing public debt has traditionally been an indicator of financial weakness and vulnerability to economic crisis in the region, there is concern for assessing whether these high levels of debt are in line with the solvency of the public sector or should be taken as a warning signal that requires policy intervention.

The goal of this paper is to assess the consistency of the public debt ratios of Brazil, Colombia, Costa Rica and Mexico with the conditions required to maintain fiscal solvency. This assessment is based on a variant of the framework proposed by Mendoza and Oviedo (2004). In particular, we apply their one-sector model with exogenous government expenditure rules. This methodology produces estimates of the short- and long-run dynamics of public debt ratios in a setup in which public revenues are subject to random shocks and the government aims to maintain its outlays relatively smooth in the face of this uncertainty. The government is handicapped in its efforts to play this insurer's role because markets of contingent claims are incomplete. The government can only issue one-period, non-state-contingent debt.

Mendoza and Oviedo (2004) show that, in this environment with incomplete contingent-claims markets, a government averse to a collapse in its public outlays and facing revenue uncertainty will impose on itself a "natural debt limit" (NDL) determined 
by the growth-adjusted annuity value of the primary balance in a state of "fiscal crisis." They define a state of fiscal crisis as the one at which a country arrives after experiencing a sufficiently long sequence of adverse shocks to public revenues and the government adjusts its outlays to minimum admissible levels.

An important implication of the NDL is that it allows the government to offer its creditors a credible commitment to remain able to repay "almost surely" at all times (including during fiscal crises). It is important to note that this commitment is not an adhoc assumption but an implication of the assumptions that (a) government is averse to suffering a collapse of its outlays, (b) public revenues are stochastic, and (c) markets of contingent claims are incomplete. However, the commitment is in terms of an "ability to pay criterion," and as such it does not rule out default scenarios that may result from "willingness to pay" or strategic reasons.

The NDL sets the upper bound for public debt but is not, in general, the same as the "sustainable" or equilibrium level of debt. The model does not require public debt to remain constant at the level of the NDL. Instead, the path of "sustainable" or equilibrium public debt depends on the initial conditions of debt and revenue, the probabilistic process driving revenues, and the policy rules governing public outlays. In the short-run, the dynamics of the distribution of public debt are driven by the government budget constraint. In the long run, depending on alternative sequences of realizations of public revenues, the government can end up retiring all the debt or hitting the debt limit. This extreme behavior of the long-run debt dynamics is particular to this basic version of the Mendoza-Oviedo model. The two-sector general equilibrium variant of their framework 
with endogenous government outlays features a unique, invariant long-run distribution of public debt (see Mendoza and Oviedo (2004) for details).

The results suggest that current debt ratios in Brazil and Colombia are near the natural debt limits that would be consistent with fiscal solvency only if one assumes perceived commitments to large reductions in non-interest outlays (in excess of 6 percentage points of GDP) in a fiscal crisis. Mexico was also near its debt limit in 1998. However, in Mexico's case the reduction in outlays that would have been needed to keep the government solvent if revenues had continued to suffer adverse shocks was smaller (at 1.5 percentage points of GDP). Still, in all three cases the implied level of adjustment in outlays to keep the government solvent in a state of fiscal crisis is more than two standard deviations below recent averages, indicating that the likelihood that the countries could produce the required adjustment in outlays if they were called to act on their perceived commitment is low. In contrast, the model indicates that Costa Rica's largest public debt ratio of the last 12 years could be financed in a state of fiscal crisis with a modest cut in outlays equivalent to 1.2 times the standard deviation of outlays.

The above results are very sensitive to underlying assumptions regarding the long-run real interest rate and growth rate. Current debt ratios in all four countries are found to be unsustainable for plausible reductions in growth rates to the averages of the last 20 years, instead of the average of the last 40 years used in the baseline scenario. Similarly, the current debt ratios are found to be unsustainable if the long-run real interest rate is set at 8 percent instead of the 5 percent value of the baseline estimates.

The Mendoza-Oviedo framework was designed as a forward-looking policy tool that intentionally sets aside the risk of default. This was done because the framework is 
intended to produce the sustainable debt ratios that a government that does not consider the option of defaulting on its obligations could support. This is in line with the assumptions of the traditional approaches to assess debt sustainability based on deterministic steady-state estimates or empirical applications of the intertemporal government budget constraint. However, while this approach is the ideal benchmark in a forward-looking policy analysis, it does have the drawback that it does not take into account how default risk considerations could affect sustainable debt dynamics. To address this issue, we study in this paper how estimates of natural debt limits and simulated debt dynamics vary when the basic Mendoza-Oviedo model is modified to incorporate exogenous default risk. Introducing default risk results in marked reductions in the levels of natural debt limits.

We also compare the results of the Mendoza-Oviedo model with those produced by the conventional methodology based on calculations of steady-state debt ratios (or "Blanchard ratios"). In the countries where the average of revenues exceeds that of outlays by a large enough margin (Costa Rica and Mexico), the Blanchard ratio yields higher debt ratios than the natural debt limits of the Mendoza-Oviedo model. This finding shows that assessments of sustainable debt based on steady-state calculations that use averages of revenues and outlays and fail to take into account aggregate, noninsurable fiscal shocks can lead countries to borrow more than what is consistent with fiscal solvency. In the countries where the averages of revenues and outlays are very similar (Brazil and Colombia), the Blanchard ratios yield negligible debt ratios. The Mendoza-Oviedo model can explain high levels of debt in these cases if the government can commit (credibly) to large enough cuts in outlays in a state of fiscal crisis. To be 
credible, however, these cuts must not represent unusually large deviations relative to the historical mean (i.e., they should not be larger than two standard deviations in percent of the mean).

The paper is organized as follows. Section 2 is a short survey of the existing methods for calculating public debt ratios consistent with fiscal solvency. Section 3 summarizes the one-good variant of the Mendoza-Oviedo model. Section 4 applies the model to the cases of Brazil, Colombia, Costa Rica and Mexico and discusses the results. This Section includes sensitivity analysis and an extension to incorporate exogenous default risk. Section 5 reflects on important caveats of the analysis and provides general conclusions.

\section{Computing Public Debt Ratios Consistent with Fiscal Solvency: A Survey}

A central question in fiscal policy discussions is how to determine whether the stock of public debt is "sustainable," in the sense of being consistent with the fiscal solvency conditions implied by current and future patterns of government revenue and outlays. Developing effective tools for computing these sustainable public debt ratios has proven a difficult task.

The first problem that studies in this area face is how to give operational content to the notion of fiscal sustainability. There is a tendency to associate the notion of unsustainable public debt with failure to satisfy the government budget constraint, or with the government holding a negative net-worth position. However, from an analytical standpoint these can be misleading because the "true" government budget constraint (as an accounting identity relating the overall public sector borrowing requirement to all sources and uses of government revenue) must always hold. Thus, an analysis that shows 
that a given stock of public debt fails a "particular" definition of the budget constraint is ultimately reflecting the fact that the analysis failed to incorporate important features of the actual fiscal situation of the country under study. How this failure translates into a judgment about the sustainability of public debt depends on assessments (typically implicit in the analysis) about the macroeconomic outcomes associated with the different mechanisms that can be used to maintain fiscal balance. Arguments about sustainability are therefore implicitly arguments about the pros and cons of these alternative mechanisms, not about whether the intertemporal budget constraint of the government holds.

Consider a basic example. In the canonical long-run analysis of public debt sustainability, we consider long-run, average levels of public revenue and expenditures, and view as the sustainable debt-output ratio the annuity value of a long-run target of the primary balance-output ratio. If a government has a large stock of contingent liabilities because of the high risk of a banking crisis, the stock of public debt may be judged to be unsustainable because, once these contingent liabilities are added, the debt-output ratio exceeds the long-run indicator of sustainability. However, the government budget constraint must hold, and thus if a banking crisis does occur the government will ultimately have to adjust the primary balance or rely on other "sources" of financing such as the inflation tax or a debt default. Adjustment via the primary balance is generally judged as consistent with this canonical view of sustainability, while adjustment via inflation or default would not because these would be viewed as alternatives inferior to adjustment of the primary balance in terms of social welfare. 
Beyond the problem of defining an operational concept of public debt sustainability, there are also problems in the design of methods for calculating sustainable debt levels. These difficulties reflect the gap between the aspects of fiscal policy emphasized in the different methods and those aspects that seem empirically relevant for explaining the actual fiscal position of governments. The literature on methods for assessing public debt sustainability reflects the evolution of ideas on these issues. In the lines below we review the main features of the different methods. The intent is not to conduct a comprehensive survey of the literature (as there are already a number of excellent surveys, see for example Chalk and Hemming (2000) or IMF (2002) and (2003a)) but to highlight the central differences among the existing methods.

The starting point of most of the existing methods for calculating sustainable public debt-output ratios is the period budget constraint of the government. This constraint is merely an accounting identity that relates all the flows of government receipts and payments to the change in public debt:

$$
B_{t+1}=B_{t}\left(1+r_{t}\right)-\left(T_{t}-G_{t}\right)
$$

where $B_{t+1}$ is the stock of public debt issued by the end of period $t, B_{t}$ is maturing public debt on which the government pays principal and the real interest rate $r_{t}, T_{t}$ is total real government revenue and $G_{t}$ are current real government outlays (i.e., $T_{t}-G_{t}$ is the primary fiscal balance).

\section{Long-Run Methods}

As the example of the long-run approach to debt sustainability given earlier illustrated, the long-run approach is based on steady-state, perfect-foresight considerations that transform the government's accounting identity (1) into an equation 
that maps the long-run primary fiscal balance as a share of output into a "sustainable" debt-to-output ratio that remains constant over time (see Buiter (1985), Blanchard (1990) and Blanchard, Chouraqui, Hagemann and Sartor (1990)). In particular, if we define the long-run rate of output growth as $\gamma$ and after some basic algebraic manipulation, the accounting identity in (1) yields:

$$
b=\frac{t-g}{r-\gamma}
$$

where $b$ is the long-run debt-to-GDP ratio, $t$ and $g$ are the long-run GDP shares of current revenue and outlays, and $r$ is the steady-state real interest rate. Condition (2) can be read as an indicator of fiscal policy action (i.e., of the "permanent" primary balance-output ratio that needs to be achieved by means of revenue or expenditure policies so as to stabilize a given debt-output ratio), or as an indicator of a "sustainable" debt ratio (i.e., the target debt-output ratio implied by a given projection of the long-run primary balance-output ratio).

\section{Intertemporal Methods}

An important shortcoming of the long-run approach is that it fails to recognize that the "long run" is essentially a theoretical construct. In the short run governments face a budget constraint that does not reduce to the simplistic (albeit significantly more tractable) formula of the long-run analysis. There can be temporarily high debt ratios, or temporarily large primary deficits, that are consistent with government solvency, and indeed incurring in such temporarily high debt or deficits could be optimal from a taxsmoothing perspective. To force a country into the straight jacket of keeping its public debt-output ratio no larger than the level that corresponds to the long-run stationary state 
can therefore be a serious mistake. The realization of these flaws in the long-run calculations led to the development of intertemporal-budget-constraint methods that shifted the focus from analyzing directly the debt-output ratio to studying the time-series properties of the fiscal balance, so as to test whether these properties are consistent with the conditions required to satisfy the government's intertemporal budget constraint. This intertemporal constraint serves as a means to link the short-run dynamics of debt and the primary balance with the long-run solvency constraint of the government.

In their original form (see Hamilton and Flavin (1986)) the intertemporal methods aimed to test whether the data can reject the hypothesis that the condition ruling out Ponzi games on public debt holds. This condition states that at any date $t$ the discounted value of the stock of public debt $t+j$ periods into the future should vanish as $j$ goes to infinity: $\operatorname{Lim}_{j \rightarrow \infty} \prod_{k=0}^{j}\left(1+r_{t+k}\right)^{-1} B_{t+1+j}=0$. In other words, in the long run the stock of debt cannot grow faster than the gross interest rate. If this no-Ponzi-game (NPG) condition holds, the forward solution of (1) implies that the intertemporal government budget constraint holds: The present value of the primary fiscal balance is equal to the value of the existing stock of debt, and hence the exiting public debt or public debt-output ratio is deemed "sustainable."

A number of articles tried different variations of this test by testing for stationarity and co-integration in the time series of the primary balance and public debt, and produced different results using U.S. data (Chalk and Hemming (2000) review this literature). These intertemporal-budget-constraint methods also began to introduce elements of uncertainty into public debt sustainability analysis, but mostly in an indirect manner as sources of statistical error in hypothesis testing, or by testing the NPG condition in 
expected value or as an orthogonality condition that considers the fact that at equilibrium the sequence of real interest rates used to discount the "terminal" debt stock must match the intertemporal marginal rate of substitution in private consumption. ${ }^{1}$

The article by Bohn (1998) provided an alternative interpretation of intertemporal methods that reduces them to testing if the primary balance responds positively to increases in public debt. In particular, if the primary balance-output ratio and the debtoutput ratio are stationary, the following regression can be used to test for sustainability:

$$
s_{t}=\rho b_{t}+\alpha \cdot Z_{t}+\varepsilon_{t}
$$

where $s_{t}$ is the ratio of the primary fiscal balance over GDP, $\varepsilon_{t}$ is a well-behaved error term and $Z_{t}$ is a vector of determinants of the primary balance other than the initial stock of public debt. In Bohn's case, he included in $Z_{t}$ the cyclical variations in U.S. GDP and a measure of "abnormal" government expenditures associated with war episodes. He found strong evidence in favor of $\rho>0$. Thus, controlling for war-time spending and the business cycle, the debt-output ratio is mean-reverting in U.S. data. Moreover, the positive coefficient $\rho$, indicating that the primary balance displays a linear response that is both positive and systematic to increases in debt, is sufficient (albeit not necessary) to ensure that the intertemporal government budget constraint holds. This is because, as the more recent methods for evaluating fiscal sustainability under uncertainty emphasize, ensuring fiscal sustainability requires that above a certain critical maximum level of debt

$$
\begin{aligned}
& { }^{1} \text { In expected value the NPG condition is } \operatorname{Lim}_{j \rightarrow \infty} E_{t}\left[\prod_{k=0}^{j}\left(1+r_{t+k}\right)^{-1} B_{t+1+j}\right]=0 \text {, in the "equilibrium" tests } \\
& \text { the condition becomes } \operatorname{Lim}_{j \rightarrow \infty} E_{t}\left[\frac{\beta^{t+1+j} u^{\prime}\left(C_{t+1+j}\right)}{u^{\prime}\left(C_{t}\right)} B_{t+1+j}\right]=0 \text {. }
\end{aligned}
$$


$b^{*}$, the primary balance responds positively (in either linear or non-linear fashion) to changes in public debt. The intuition is that if this is the case any large increase in debt due to "large negative shocks" is eventually reversed through primary surpluses.

Chapter III of IMF (2003b) applied Bohn's method to a panel of industrial and developing country data. The results identified a group of developing countries where the sustainability condition $\rho>0$ holds, and others where it does not. Moreover, the study also shows evidence of non-linearities in the relationship between debt and primary balances, indicating that countries that were able to sustain larger debt ratios in the data also displayed a stronger response of the primary balance to debt increases.

\section{Recent Development: Probabilistic Methods and Methods with Financial Frictions}

Recent developments in public debt sustainability analysis follow two strands.

The first strand emphasizes the fact that governments, particularly in emerging markets, face significant sources of uncertainty as they try to assess the patterns of government revenue and expenditures, and hence the level of debt that they can afford to maintain. From the perspective of these probabilistic methods, measures of sustainability derived from the long-run approach or the intertemporal analysis are seen as inaccurate for governments that hold large stocks of debt and face large shocks to their revenues and expenditures. The key question here is not whether public debt is sustainable at some abstract steady state, or whether in a sample of a country's recent or historical past the NPG condition holds. The key question is whether the current debt-output ratio is sustainable given the current domestic and international economic environment and its future prospects. 
The second strand aims to incorporate elements of the financial frictions literature applied to the recent emerging-markets crises. For example, public debt in many emerging markets displays a characteristic referred to as "liability dollarization" (i.e., debt is often denominated in foreign currency or indexed to the price level.). As a result, abrupt changes in domestic relative prices that are common in the aftermath of a large devaluation, or a 'sudden stop' to net capital inflows, can alter dramatically standard long-run calculations of sustainable debt ratios and render levels of debt that looked sustainable in one situation unsustainable in another. Calvo, Izquierdo and Talvi (2003) evaluate these effects for the Argentine case and find that large changes in the relative price of nontradables alter significantly the assessments obtained with standard steadystate sustainability analysis. The general version of the Mendoza-Oviedo model also incorporates these effects (see Mendoza and Oviedo (2004)).

The probabilistic methods for assessing fiscal sustainability propose alternative strategies for dealing with macroeconomic uncertainty. A method proposed at the IMF by Barnhill and Kopits (2003) incorporates uncertainty by adapting the value-at-risk (VaR) principles of the finance industry to debt instruments issued by governments. The aim of this approach is to model the probability of a negative net worth position for the government. The method requires estimates of the present values of the main elements of the balance sheet of the total consolidated public sector (financial assets and liabilities, expected revenues from sales of commodities or other goods and services, as well as any contingent assets and liabilities), and an estimate of the variance-covariance matrix of the variables that are viewed as determinants of those present values in reduced form. This information is then used to compute measures of dispersion relative to the present values 
of the different assets and liabilities that determine the value at risk (or exposure to negative net worth) of the government.

A second probabilistic method recently considered for country surveillance at the IMF (see IMF (2003c)) modifies the long-run method to incorporate variations to the determinants of sustainable public debt in the right-hand-side of equation (2), and also examines short-term debt dynamics that result from different assumptions about the short-run path of the variables that enter the government budget constraint in deterministic form. For example, deterministic debt dynamics up to 10 periods into the future are computed for variations of the growth rate of output of two standard deviations relative to its mean.

The same IMF publication proposes a stochastic simulation approach that computes the probability density function of possible debt-output ratios. This stochastic simulation model, like the VaR approach, is based on a non-structural time-series analysis of the macroeconomic variables that drive the dynamics of public debt (particularly output growth, interest rates, and the primary balance). The difference is that the stochastic simulation model produces simulated probability distributions based on forward simulations of a vector-autoregression model that combines the determinants of debt dynamics as endogenous variables with a vector of exogenous variables. The distributions are then used to make assessments of sustainable debt in terms of the probability that the simulated debt ratios are greater or equal than a critical value. $\mathrm{Xu}$ and Ghezzi (2002) developed a third probabilistic method to evaluate sustainable public debt. Their method computes "fair spreads" on public debt that reflect the default probabilities implied by a continuous-time stochastic model of the dynamics 
of treasury reserves in which exchange rates, interest rates, and the primary fiscal balance follow Brownian motion processes (so that they capture drift and volatility observed in the data). The analysis is similar to that of the first-generation models of balance-ofpayments crises. Default occurs when treasury reserves are depleted, and thus debt is deemed unsustainable when the properties of the underlying Brownian motions are such that the expected value of treasury reserves declines to zero (which occurs at an exponential rate).

\section{The Basic Version of the Mendoza-Oviedo Model}

The probabilistic methods summarized in the last section make significant progress in incorporating macroeconomic uncertainty into debt sustainability analysis but they are largely based on non-structural econometric methods. In contrast, the Mendoza Oviedo (MO) method aims to provide an explicit dynamic equilibrium model of the mechanism by which macroeconomic shocks affect government finances. The MO method also differs from the other probabilistic methods in that it models explicitly the nature of the government's forward-looking commitment to remain solvent, instead of focusing on computing estimates of exposure to negative net worth or depletion of treasury reserves. As explained below, the MO method determines sustainable debt ratios that respect a natural debt limit consistent with a credible commitment to repay similar in principle to the one implicit in the long-run and intertemporal methods.

The structural emphasis of the MO approach comes at the cost of the reduced flexibility and increased complexity of the numerical solution methods required to solve non-linear, dynamic stochastic equilibrium models with incomplete asset markets. At the same time, by proceeding in this manner the MO framework seeks to produce estimates 
of sustainable public debt that are robust to the Lucas critique. The non-structural or reduced-form tools used in the other probabilistic methods to model the dynamics of public debt are vulnerable to the policy instability problems resulting from the Lucas critique. This is not a serious limitation when these methods are used for an ex-post evaluation of how well past debt dynamics matched fiscal solvency conditions, but it can be a shortcoming for a forward-looking analysis that requires a framework for describing how equilibrium prices and allocations, and hence the ability of the government to raise revenue and service debt, adjust to alternative tax and expenditure policies or other changes in the environment (including, for example, a Sudden Stop limiting the access to international capital markets or a collapse in the real exchange rate triggered by a devaluation of the currency).

The basic principles of the MO method are as follows. Assume that output follows a deterministic trend (so that it grows at a constant, exogenous rate $\gamma$ ) and the real interest rate is constant. Public revenues follow an exogenous stochastic process. The government is extremely averse to suffering a collapse in its outlays. Hence, it aims to keep its outlays smooth unless the loss of access to debt markets forces it to adjust them to minimum tolerable levels. The government can only issue non-state-contingent debt. The government budget constraint in (1) can then be re-written as:

$$
(1+\gamma) b_{t+1}=b_{t}(1+r)-\left(t_{t}-g_{t}\right)
$$

where lowercase letters refer to ratios relative to GDP.

Since the government wants to rule out a collapse of its outlays below their tolerable minimum levels, it would not want to borrow more than the amount of debt it could service if the primary balance were to remain forever (or "almost surely" in the 
language of probability theory) at its lowest possible value, or "fiscal crisis" state. A state of fiscal crisis is defined as a situation reached after a "sufficiently" long sequence of the worst realization of public revenues and after public outlays have been adjusted to their tolerable minimum. This upper bound on debt is labeled the "Natural Debt Limit" (NDL), which is the term used in the precautionary-savings literature for an analogous debt limit that private agents impose on themselves when they can only using non-statecontingent assets to try to smooth consumption (see Aiyagari (1994)). The NDL is given by the growth-adjusted annuity value of the primary balance in the state of fiscal crisis.

The "history of events" leading to a fiscal crisis has non-zero probability (although it could be a very low probability) as long as that crisis state is an event within the support of the probability distribution of the primary balance, and as long as there are non-zero conditional probabilities of moving into this crisis state from other realizations of the primary balance. Under these conditions, the government knows that there is some probability that it could suffer a fiscal crisis in the future, and to ensure it can pay for its minimum level of outlays it must not hold more debt than it could service then.

Since the NDL is a time-invariant debt level that satisfies the government budget constraint with revenues and outlays set at their minimum, it follows that the NDL implies that the government remains able to service its debt even in a state of fiscal crisis. Thus, the NDL that a government imposes on itself in order to self-insure so as to rule out a collapse of public outlays below its tolerable minimum also allows that government to offer lenders a credibly commitment to remain able to repay its debt in all states of nature. 
To turn the above notions of the NDL and its implied credible commitment to repay into operational concepts, we need to be specific about the factors that determine the probabilistic dynamics of the components of the primary balance. On the revenue side, the probabilistic processes driving tax revenues reflect the uncertainty affecting tax rates and tax bases. These processes have one component that is the result of domestic policy variability and the endogenous response of the economy to this variability, and another component that is largely exogenous to the domestic economy (which typically results from the nontrivial effects of factors like fluctuations in commodity prices and commodity exports on government revenues). The one-sector version of the MO model used in this paper incorporates explicitly the second component. ${ }^{2}$

On the expenditure side, government expenditures adjust largely in response to policy decisions, but the manner in which they respond varies widely across countries. Industrial countries tend to display countercyclical fiscal policies while fiscal policy in emerging markets is generally procyclical (as the recent literature on procyclical fiscal policy has shown). In addition, the "adjustment" or minimum level of public outlays to which the government can commit to adjust in a fiscal crisis is particularly important for determining the NDL and the sustainable debt ratios in the MO model.

Labeling the fiscal-crisis level (or lowest realization) of the government revenueGDP ratio as $t^{\min }$ and the minimum level of the ratio of outlays to GDP that the government can commit to deliver as $g^{\min }\left(\right.$ for $\left.g^{\min }<t^{\min }\right)$, it follows from the government budget constraint in (4) that the NDL is the value of $b^{*}$ given by:

\footnotetext{
${ }^{2}$ Note that the exogenous determinants of public revenue dynamics can be important even in economies that have successfully diversified their exports away from primary commodities. In Mexico, for example, oil exports are less than 15 percent of total exports but oil-related revenues still represent more than $1 / 3$ of public sector revenue.
} 


$$
b_{t+1} \leq b^{*} \equiv \frac{t^{\min }-g^{\min }}{r-\gamma}
$$

This NDL is lower for governments that have (a) higher variability in public revenues (for example, if fiscal revenue follows a symmetric Markov chain that obeys the rule of simple persistence, the value of $t^{\min }$ can be written as a multiple of the standard deviation of public revenues and hence lower values of $t^{\min }$ reduce the debt limit), (b) less flexibility to adjust public outlays, and (c) lower growth rates or higher real interest rates.

The NDL represents a credible commitment to repay in the sense that it ensures that the government remains able to repay even in a state of fiscal crisis for a given known stochastic process driving revenues and a given policy setting the minimum level of outlays. However, this should not be interpreted as suggesting that the need to respect the NDL rules out the possibility of sovereign default. Default triggered by "inability to pay" remains possible if there are large, unexpected shocks that drive revenues below what was perceived to be the value of $t^{\min }$ or if the government turns out to be unable to reduce outlays to $g^{\text {min }}$ when a fiscal crisis hits. In addition, default triggered by "unwillingness to pay" remains possible since the NDL is only an ability to pay criterion that cannot rule out default for strategic reasons. Later in Section 4 we explore an extension of this framework that incorporates default risk into the basic MO setup. Consider a government with exogenous, random fiscal revenues (say, for example, oil export revenues) and an ad-hoc smoothing policy rule for government expenditures, such that $g_{t}=g$ (for $g \geq g^{\min }$ ) as long as $b_{t+1} \geq b^{*}$, otherwise $g_{\mathrm{t}}$ adjusts to satisfy condition (4). By (4) and (5), if at a particular date the current debt ratio is below $b^{*}$ and the realization of the revenue-output ratio is $t^{\min }$, the government finances $g$ by 
increasing $b_{t+1}$. In contrast, if at some date the current debt ratio is at $b^{*}$ and the realization of revenues is $t^{\mathrm{min}}$, (4) and (5) imply that $g_{t}=g^{\mathrm{min}}$.

In a simple example with zero initial debt, it is straightforward to show that if the government keeps drawing the minimum realization of public revenue, it will take the $\mathrm{T}$ periods that satisfy the following condition for the government to hit the NDL:

$$
\left(\frac{R}{\gamma}\right)^{T}=\frac{g-g^{\min }}{g-t^{\min }}
$$

This result indicates that, in the worst-case scenario in which revenues remain "almost surely" at their minimum, the government can access the debt market to keep the ratio of public outlays at the level $g$ for a longer period of time the larger is the excess of "normal" government outlays over minimum government outlays relative to the excess of normal outlays over the minimum level of revenues. Thus, the government uses debt to keep its outlays as smooth as possible given its capacity to service debt as determined by the volatility of its public revenues, reflected in the value of $t^{\min }$, and its ability to reduce public outlays in a fiscal crisis, reflected in the value of $g^{\min }$.

It is critical to note that the key element of the expenditure policy is not the level of $g^{\text {min }}$ per se but the credibility of the announcement that outlays would be so reduced during a fiscal crunch. The ability to sustain debt and the credibility of this announcement depend on each other because a government with a credible ex ante commitment to major expenditure cuts during a fiscal crisis can borrow more and access the debt market for longer time, and hence, everything else the same, this government faces a lower probability to be called to act on its commitment. In a more general case in which public revenue is not an exogenous probabilistic process but it is in part the result 
of tax policies and their interaction with endogenous tax bases, the credibility argument extends to tax policy. Governments that can credibly commit to generate higher and less volatile tax revenue-output ratios will be able to sustain higher levels of debt, and to the extent that this helps the economy produce stable tax bases it helps support the credibility of the government's ability to raise revenue.

The condition defining the NDL in (5) has a similar form as the formula for calculating sustainable debt ratios under the long-run method: $b=\frac{t-g}{r-\gamma}$. However, the implications for assessing fiscal sustainability under the two methods are sharply different. In general, the long-run deterministic rule will always identify as sustainable a debt-output ratio that is unsustainable once uncertainty of the determinants of the fiscal balance and the NDL are taken into account. This is because the long-run method ignores the role of the volatility of the elements of the fiscal balance, while in the MO model one finds that, everything else the same, governments with less variability in tax revenues can sustain higher debt ratios.

Consider the case of two governments with identical long-run averages of tax revenue-output ratios at 20 percent. The tax revenue-output ratio of government $\mathrm{A}$ has a standard deviation of 1 percent relative to the mean, while that of Government B has a standard deviation of 5 percent relative to the mean. Assuming for simplicity that the distributions of tax revenue-output ratios are Markov processes with $t^{\min }$ set at two standard deviations below the mean, the probabilistic model would compute the natural debt limit for A using a value of $t^{\min }$ of 18 percent, while for B it would use 10 percent. The deterministic long-run method yields the same debt ratio for both governments and uses the common 20 percent average tax revenue-output ratio to compute it. In contrast, 
the MO method would find that debt ratio unsustainable for both governments and would produce a debt limit for B that is lower than that for A.

Another important difference between the two methods is in the way that the MO method views the debt limit vis-à-vis the way in which the long-run method views the steady-state debt ratio. In the long-run analysis, the debt ratio is viewed as either a target ratio to which a government should be forced to move to, or as the anchor for a target primary balance-GDP ratio that should be achieved by means of a policy correction. In contrast, in the MO method condition (5) defines only the maximum level of debt. Unless the NDL binds, this maximum level of debt is not the equilibrium or sustainable level of debt that should be issued by the government (although it clearly plays a central role in determining both). Depending on the probabilistic and policy assumptions driving revenues and expenditures (and, generalizing condition (5), depending also on the stochastic processes of the real interest rate and output growth), a country can have levels of debt lower (even much lower) than this critical level, and may take a very long time on average to enter a state of fiscal crisis or even never arrive at it.

The MO methodology models uncertainty in the form of discrete Markov processes. Given information on the current stock of public debt, the current tax revenue-GDP ratio and the assumed behavioral rules for government outlays and statistical moments of the public revenue process, the model produces conditional oneperiod-ahead and unconditional long-run distributions of the debt-output ratio, as well as estimates of the average number of periods in which $b^{*}$ is expected to be reached from any initial $b_{t}$. Again, depending on the nature of the stochastic processes and policy rules 
of revenues and outlays, it may take a few quarters to hit the debt ceiling on average or it may take an infinite number of quarters to do it

\section{Results of the MO Method for Brazil, Colombia, Costa Rica \& Mexico}

This Section applies the MO method described in the last section to the cases of Brazil, Colombia, Costa Rica and Mexico. The Section begins with a brief review of the recent growth performance and evolution of public debt, public revenues and public expenditure ratios in these countries. This review serves to identify key parameters needed to simulate the debt dynamics and solve for natural debt limits.

\section{Review of Growth Performance and Fiscal Dynamics}

The growth performance of the four countries examined in this study over the last two decades was weak. As shown in Table 1, average growth in GDP per capita for the period 1981-2000 ranged from a minimum of 0.5 percent in Brazil to a maximum of 1.25 percent in Costa Rica. These countries grew at faster rates in the past. Taking averages starting in 1961, the smallest average per-capita GDP growth rate was 1.8 percent for Costa Rica and the largest was 2.6 percent for Brazil. Given the apparent structural breaks in the trend of GDP per capita of these countries since the early 1980s, we conduct our public debt analysis under a baseline growth scenario that uses 1961-2000 average growth rates, and compare the results with a scenario that views the growth slowdown of the last two decades as permanent by using 1981-2000 average growth rates.

Reliable cross-country estimates of public debt stocks and interest rates on public debt at the general government level are hard to obtain. We use the figures documented in IMF (2003b) for ratios of public debt to GDP for the period 1990-2002. As shown in Table 1, the mean debt-GDP ratios for the full sample range from 33.7 percent in 
Colombia to 49.5 percent in Costa Rica. However, these full-sample averages hide the fact shown in Figure 1 that debt ratios have been growing rapidly (except in the case of Costa Rica, where the ratio has been fairly stable but also fairly high). If we split the sample to create averages for 1990-1995 and 1996-2002, we find that the mean debt ratios of Brazil, Colombia and Mexico increased by about 10 percentage points between the first period and the second periods. By the end of the sample period, all four countries displayed debt ratios of about 50 percent (see Figure 1). The key question to answer is therefore whether a debt ratio of 50 percent is consistent with fiscal solvency given the pattern of growth and interest rates and the volatility of fiscal revenues that these countries face.

Real interest rates on public debt are hard to measure because of differences in maturity, currency denomination, indexation factors, and residence of creditors for the various debt instruments that each country issues, and also because of the existence of time-varying default and exchange-rate risk premia. One useful proxy is the measure of sovereign risk proposed by Neumeyer and Perri (2003), which is the spread of the EMBI+ index relative to the U.S. T-Bill rate deflated by an estimate of expected inflation in the U.S. GDP deflator. The sample period of this measure is relatively short (starting in 1994) and biased because it includes mainly observations for a turbulent period in world capital markets. Still, this measure of real interest rates on public debt shows substantial premia over the world's risk free rate (the average real interest rates including the risk premia for a quarterly sample from 1994:1 to 2002:2, are 12.9 percent for Brazil and 10.3 percent for Mexico). The real interest rate on debt instruments will deviate from these figures to the extent that (a) debt instruments are domestic rather than external, (b) 
debt is denominated in domestic currency rather than in foreign currency or in terms of an indexation factor, and (c) the debt instruments have liquidity or transactions value for the holders. The lower bound of the interest rate on public debt is set by the real interest rate on U.S. public debt. The 1981:1-2000:4 average of the U.S. 90 day T-bill rate deflated by observed U.S. CPI inflation is about 2.8 percent.

Given the above considerations, we consider two interest rate scenarios in our calculations. The baseline scenario considers a real interest rate of 5 percent, which incorporates a small long-run default risk premium of about 2.2 percentage points above the U.S. T-bill rate. The alternative is a high-real-interest-rate scenario in which the real interest rate is set at 8 percent (i.e., the long-run default risk premium is about 5.3 percentage points above the T-bill rate). In both scenarios we remain relatively optimistic about growth prospects, using average growth rates for the period 1961-2000.

The measure of public revenues that we need to isolate for conducting the debt analysis is the total of all tax and non-tax government revenues excluding grants. For government expenditures we require the total non-interest government outlays (including all expenditures and transfer payments and excluding all forms of debt service). Once again, limitations of the existing international databases make it difficult to retrieve consistent measures of these variables that apply at the level of the entire non-financial public sector and, in the case of the outlays, that include the annuity values of all contingent liabilities resulting from obligations like banking- or pension-system bailouts. We put together estimates of the revenue and outlay ratios for the four countries under study by combining data from IMF (2003b) and World Development Indicators (see the footnotes to Table 1 for details). The former shows data for the non-financial public 
sector but it does not separate interest and non-interest expenditures for some countries. The latter separates interest and non-interest expenditures but reports data only for the central government. Thus, the revenue and expenditures data are not exactly comparable across countries.

The average ratios of total public revenue to GDP during the period 1990-2002 ranged from 12.6 percent in Colombia to 23 percent in Mexico (Table 1). Turning to examine the volatility of public revenues, Costa Rica displays the lowest coefficient of variation in the revenue-output ratio, at 5.4 percent of the mean. The coefficient of variation of revenues is similar in Colombia and Mexico (8.9 and 8 percent respectively). Brazil shows the highest coefficient of variation of public revenues at 14.1 percent. Interestingly, the country with the lowest coefficient of variation in public revenues (Costa Rica) is also the one with the highest average public debt-GDP ratio.

The average of total non-interest outlays as a share of GDP is very similar in Brazil, Costa Rica and Mexico, at about 19 percent. The average outlays ratio for Colombia is much lower, at 12.8 percent, but this is one of the measures that applies only to the central government, so the actual ratio for the non-financial-public sector must be higher. With regard to the variability of non-interest outlays, Mexico shows the smallest coefficient of variation (about 4 percent), followed by Costa Rica (10 percent). Brazil and Colombia show the highest coefficients of variation in the outlays ratio, at about 14 percent for both.

Natural Debt Limits: Baseline Scenario and Two Alternatives

Table 1 reports three sets of calculations of natural debt limits for Brazil, Colombia, Costa Rica and Mexico. The baseline scenario considers the 1961-2000 
average growth rates of GDP per capita and a 5 percent real interest rate. The growthslowdown (GS) scenario uses the 1981-2000 average growth rates (with the real interest rate still at 5 percent). The high-real-interest-rate (HRIR) scenario uses a real interest rate of 8 percent (with the growth rates set at the 1961-2000 averages).

The baseline scenario differs from the other two because it is designed to produce a coefficient of fiscal adjustment that yields an NDL equal to the largest debt ratio observed for each country in the 1990-2002 period. Table 1 reports this coefficient of "implied fiscal adjustment" in terms of how many standard deviations relative to the mean of non-interest outlays are needed to yield a debt limit equal to maximum observed debt (given the data for means and coefficients of variation of revenues and outlays, the average growth rates, the real interest rate, and assumed floors of public revenue equal to two standard deviations below the corresponding means). The Table also shows the implied minimum ratio of outlays to GDP resulting from the coefficient of fiscal adjustment. The GS and HRIR scenario keep the same fiscal adjustment coefficient and just alter either the growth rate or the real interest rate.

The public debt-GDP ratios of the four countries under study peaked at similar levels during the 1990-2002 period (ranging from 50 percent in Colombia to 56 percent in Brazil). The coefficients of implied fiscal adjustment reported in Table 1 show that, in order to produce NDLs that can support these high levels of debt, three of the four countries (Brazil, Colombia and Mexico) need credible commitments to undertake large cuts in outlays if they were to hit a fiscal crisis. The adjustment measures 2 standard deviations below the mean of non-interest government outlays in Mexico, 2.3 in Colombia and 2.6 in Brazil (which are equivalent to cuts relative to the average outlays- 
GDP ratios of 1.5, 4 and 6.7 percentage points respectively). The fact that these adjustments are outside the two-standard-deviation threshold of the data for non-interest outlays of the previous decade suggests that the probability that the governments could produce these large expenditure cuts if they needed to act on their commitment is low.

The situation in Costa Rica seems more favorable. Costa Rica can support a credible commitment to repay a debt-output ratio as large as 53 percent of GDP with a fiscal adjustment of 1.2 standard deviations below the mean of non-interest outlays (which is equivalent to about 2 percentage points of GDP). Thus, the model is consistent with the data in predicting that Costa Rica, the country with less volatility in public revenues, should be the one that has a better chance of sustaining a high debt ratio. This is the case even though Costa Rica's growth rate is the same as Colombia's and is lower than the growth rates in Mexico and Brazil by 0.4 and 0.7 percentage points respectively.

The potential dangers of using the Blanchard ratios for conducting debt sustainability analysis are illustrated in the baseline results. The case of Mexico is particularly striking. The Blanchard ratio, which would compute a sustainable debt ratio using the difference between the average public revenue and the average government outlays, yields a debt ratio of about 132 percent, nearly 2.5 times larger than the NDL produced by the MO model. In the case of Costa Rica, the Blanchard ratio also exceeds the NDL but by a very small margin. In contrast, in the cases of the two countries where complying with the NDLs would require the largest expenditure cuts (i.e., where the consistency of the high debt ratio with fiscal solvency is more questionable), the Blanchard ratio yields public debt ratios so low that are of little practical relevance. The Blanchard ratio for Brazil is 3.5 percent and for Colombia the ratio is negative, at -5.3 
percent (because in the data the average outlays exceed the average revenues by 0.16 percentage points of GDP). In these cases the Blanchard ratio would be switched to its alternative interpretation, where a target debt ratio would be chosen and the Blanchard ratio would then be used to set an average primary fiscal balance that the governments should aim to obtain by adjusting fiscal policy.

Consider next the natural debt limits in the GS and HRIR scenarios. If the growth slowdown of the last two decades persists, and even assuming that the coefficients of fiscal adjustment were to remain as high as estimated in the baseline scenario, the current debt ratios would exceed the natural debt limits of all four countries by large margins. The situation of Brazil would be particularly compromised, because the current debt ratio of 56 percent would exceed the maximum debt ratio consistent with a fully credible commitment to repay in the GS scenario by nearly 26 percentage points of GDP.

The HRIR scenario, in which for example a retrenchment of world capital markets, increased long-run default risk, or the pressure of large fiscal deficits in industrial countries push the real interest rate on emerging markets public debt to 8 percent, has even more damaging effects. In this case, even if the growth rates recover to the 1961-2000 averages and even with the large fiscal adjustment coefficients set in the baseline scenario, the natural debt limits of all four countries fall to a range between 25.2 percent for Brazil to 27.4 percent for Costa Rica. Notice, however, that the prediction of the model is not that an increase of the interest rate to 8 percent would trigger immediate fiscal crises in all four countries. For a fiscal crisis to occur immediately, the increase in the interest rate would have to be once-and-for-all and permanent. A transitory hike in the real interest rate could be absorbed in an analogous manner as a transitory downturn 
in public revenues, and hence a fiscal crisis would only be triggered after a sufficiently long sequence of adverse shocks.

This last observation highlights again the fact that the NDL is not (in general) the same as the sustainable or equilibrium level of debt, which is determined by the dynamics driven by the government budget constraint. We turn now to study these dynamics.

\section{Debt Dynamics}

The simulations of debt dynamics consider a grid of public debt-GDP ratios that spans the interval from 0 to the NDL (the model assumes that if the government budget constraint yields negative debt at any time, the corresponding fiscal surplus is instead rebated to the private sector as a lump-sum transfer). The dynamics of sustainable debt can be traced from any initial public debt ratio in this interval. However, one needs to be careful in studying the long-run dynamics of debt ratios because this basic version of the MO model features at least two long-run distributions of public debt, one converging to 0 and the other to the NDL. Which of these two distributions is attained in the long run depends on initial conditions.

The prediction that the long-run debt ratio is not determined within the model (i.e., that the long-run debt ratio depends on initial conditions) is not a peculiarity unique to the MO model. An outcome like this is the key prediction for debt dynamics of the classic tax-smoothing framework of Barro (1979), and it is also in line with the findings on Ramsey optimal taxation problems in which smooth taxes are optimal taxes (see Chapter 12 of Ljungqvist and Sargent (2000)).

The stochastic processes of public revenues used in the simulations are characterized by time-invariant Markov chains. The Markov chains are defined by three 
objects: an $n$-element vector of realizations of the revenues, $t$, an $n x n$ transition probability matrix, $P$, and a probability distribution for the initial value of the realization of revenues, $\pi_{0}$. The typical element of $P, P_{\mathrm{ij}}$, indicates the probability of observing revenues $t=t_{j}$ in the next period given that revenues are $t=t_{i}$ in the current period.

For each country, the vector of realizations of revenues has 5 elements $(n=5)$. The lowest value of $t$ is set two standard deviations below average revenues in each of the four countries under analysis. We use Tauchen's (1986) univariate quadrature method in order to construct the rest of the elements of $t$ and the matrix $P$ so as to approximate the first-order autocorrelation and standard deviation of public revenues observed in the data.

The stochastic simulations require also that we generate a $T$-period time series of realizations of revenues, i.e. $t_{1}, t_{2}, \ldots t_{T}$, drawn from the Markov vector $t$. This time series is constructed using realizations of a uniform random variable $u$ in $[0,1]$ that indicates how to pick one realization of tax revenue in period $t+1$ given the realization at time $t$. The tax revenue at $t+1, t_{j}$ say, is determined according to:

$$
\sum_{l=1}^{j} P_{i, l}<u \leq \sum_{l=1}^{j+1} P_{i, l}
$$

or $t_{j}=t_{l}$ if $u<P_{i l}$

The first application of the stochastic simulations is illustrated in Figure 2, which shows the number of periods that it takes to hit a fiscal crisis (i.e., to hit the NDL) for the country-specific calibrated parameters and seven initial debt ratios that span the range between 0.25 and the maximum debt ratio observed in each country in the 19902002 sample. From each initial condition of the debt ratio, there are different stochastic paths that public debt, revenues and outlays can follow in the future, and each of these paths features a different number of periods to hit a fiscal crisis. The tall bars in the 
figure report the average time to a fiscal crisis from 1000 simulations of the public-debt dynamics induced by the government budget constraint in equation (4). The simulated tax revenues correspond to the realizations of revenues drawn from the Markov chains calibrated to the revenue processes of each country (see Table 1 for the corresponding averages and coefficients of variation). Depending on initial conditions, there are simulation in which a fiscal crisis never occurs (particularly for low initial debt ratios). In these cases, the average measure of time to fiscal crisis would go to infinity, and hence is omitted from the charts.

The short bars in the plots show the minimum possible number of periods before hitting the fiscal crisis. This extreme adverse scenario corresponds to simulations of debt dynamics under the assumption that, in every period, the government draws the lowest realization of the public revenue contained in the vector of realizations of revenues.

The top two graphs in Figure 2 show that in Brazil and Colombia the mean time to a fiscal crisis is high ( 15 years or more) for an initial debt ratio equal to 0.25 . A fiscal crisis can occur much sooner on average (in less than 2.5 years) when then initial debt ratio is around 0.5 . The difference between the mean and extreme time to hit a fiscal crisis is larger in Brazil than in Colombia for all initial debt ratios. Furthermore, the extreme scenario indicates a shorter time to a fiscal crisis in Brazil than in Colombia regardless of the initial debt ratio. This is because the lowest realization of revenues are calibrated to be two standard deviations below the mean, so the higher volatility of revenues in Brazil implies that the crisis-level of revenues for Brazil is more distant from the mean than for Colombia. 
The bottom two graphs in Figure 2 (for the cases of Costa Rica and Mexico) serve to illustrate how uncertainty affects the dynamics of public debt and the fact that the NDL is not in general the same as the equilibrium or sustainable debt. The fact that these plots only show bars for the mean time to a fiscal crisis for high debt ratios (above 50 percent) indicates that in the sampling of 1000 stochastic simulations starting from debt ratios below 0.5 , there were many cases in which the debt ratio converged to zero instead of reaching the NDL. Consider for example the initial debt ratio of about 0.35 in the plot for Costa Rica. The extreme measure of time to a fiscal crisis shows that a fiscal crisis will occur after 10 years of experiencing realizations of revenues two-standard-deviations below the mean. However, in the 1000 stochastic simulations used to calculate the mean time to a fiscal crisis, only about half of the simulations reached the NDL and the rest converged to a zero public debt position in the long run. Similarly, for an initial debt ratio of 0.4 , the debt ratio never reached the NDL in 127 out of 1000 simulations. Thus, the Costa Rican and Mexican cases illustrate examples in which the sustainable debt dynamics deviate sharply from the NDL.

Figure 3 shows a sample of simulated time series of the public debt ratio and illustrates further how much the NDL and the sustainable debt ratios differ. The figure shows 50 simulations of debt ratios all starting from a common initial ratio of 0.35 , using the parameter values calibrated to Costa Rica. At each date $t$, a random draw of public revenues, along with the date- $t$ debt and the fiscal rules for public outlays, are used to determine the value of the debt at $t+1$. Notice that, whereas for some paths the debt ratio increases rapidly to reach the NDL, for other paths it takes a long time to reach it and for other paths the debt goes to zero. As explained above, for a large range of initial values 
of public debt the model predicts that debt ratio will reach the debt limit while for other initial values the debt ratio goes to zero. This implies that for starting values of the debt ratio above 0.35 , the fraction of paths driving the debt to its maximum level increases and for starting values below 0.35 that fraction decreases.

\section{Default Risk}

Up to this point we followed the methodology proposed by Mendoza and Oviedo (2004) in which sovereign default was set aside to focus on modeling the optimal debt policy consistent with fiscal solvency and an ad-hoc rule smoothing public outlays.

Default risk was only taken into account in setting the value of the long-run real interest rate used to solve for the NDLs and the debt dynamics ( 5 percent in the benchmark case, 8 percent in the high-interest-rate scenario). However, time-varying default risk premia are an important feature of public debt in emerging markets. It may make sense for a government to conduct a forward-looking debt sustainability exercise in which it assumes that default risk is time invariant as a benchmark scenario, but it is important to study how the results change when time-varying default risk is introduced.

One important limitation of the analysis of default risk is that existing theoretical models of default on optimal sovereign debt contracts face serious challenges in explaining observed debt ratios. The canonical model of Eaton and Gersovitz (1981) considers a risk-neutral lender and a risk-averse borrower that has the option of defaulting at the cost of facing permanent exclusion of the debt market. The lender is willing to take on the risk of default by charging a rate of interest that incorporates a premium consistent with the probability of repayment (as implied by a standard arbitrage condition between the expected repayment on defaultable debt and the return on risk-free 
bonds). There are well-known theoretical problems with this setup, related to the classic Bulow-Rogoff critique showing that the threat of exclusion may not be credible because of the option to enter in deposit contracts with lenders, but even if the model were not affected by these problems, recent quantitative studies show that models in the EatonGersovitz tradition support very small debt ratios of less than 10 percent of GDP (see Arellano (2004)). This is because the models yield probabilities of default that increase too rapidly at very low levels of debt.

Given the above difficulties with the theory of endogenous default risk, we follow a pragmatic approach that takes into account the same risk-neutral lender of the EatonGersovitz model but incorporates an exogenous probability of repayment calibrated to match observed default risk premia in emerging markets. The arbitrage condition of the risk-neutral lender implies:

$$
R\left(b_{t}\right)=\frac{R^{w}}{\lambda\left(b_{t}\right)}=\frac{R^{w}}{\exp \left(-a b_{t}\right)}, \quad a>0
$$

In this expression, $R^{w}$ is the gross world risk-free real interest rate and $\lambda\left(b_{t}\right)$ is the probability of repayment (i.e., $1-\lambda\left(b_{t}\right)$ is the probability of default). The repayment probability is modeled as an exponential probability distribution $\exp \left(-a b_{t}\right)$, where the curvature parameter $a$ determines the speed at which the repayment probability falls as debt increases.

The exponential formulation of default risk has the advantage that it is consistent with two key properties of the endogenous default probability of the Eaton-Gersovitz line of models: (a) the probability of default is increasing and convex on the level of debt and (b) the probability of default is zero if the stock of debt is zero. The formulation fails to 
reproduce the property of the Eaton-Gersovitz setup that the probability of default approaches 1 for a finite "rationing" level of debt at which debtors always find it preferable to default than to repay (the exponential probability of default approaches 1 asymptotically as debt goes to infinity). However, the formulation still allows for values of $a$ that yield very large risk premia for high levels of debt comparable to those observed in the data.

We calibrate the value of $a$ so that the arbitrage condition in (7) holds taking as given the EMBI+ country risk premium and the public debt ratio observed in Mexico in 1998 (the year of Mexico's maximum debt ratio in the 1990-2002 sample). Mexico's debt ratio in 1998 was $b_{t}=0.549$ and the real interest rate that the country faced on this debt, measured as the U.S. 90-day T-bill rate plus the EMBI+ spread, was $R\left(b_{t}\right)=10.48$ percent. The risk-free rate (i.e., the real U.S. 90-day T-bill rate) was $R^{w}=3.2$ percent. Plugging these figures into (7) and solving for $a$ yields $a=0.124$. Interestingly, the observed maximum debt and the real interest rate with default premium for Brazil in the year 2002 are very similar to Mexico's 1998 figures (Brazil's debt ratio was 0.56 and the real interest rate with default risk was 10.8 percent). This suggests that using a common value of $a$ for the four countries under study is not a bad first approximation.

As we show below, default risk has two important implications for the analysis of sustainable debt based on the MO model. First, it lowers the levels of NDLs, since the real interest rates considered in Table 1 are lower than those resulting in the worst state of nature with default risk. Second, it alters the dynamics of public debt, since the rate of interest now increases with the level of debt. These two effects result in lower NDLs, reduced levels of sustainable debt and faster convergence to states of fiscal crisis. 
Table 2 shows the effects of introducing time-varying default risk in the calculations of NDLs. ${ }^{3}$ In all the estimates shown in this Table, the risk free rate is set at the 1990-2002 average of the real 90-day T-bill rate, which is 2.36 percent, and the curvature parameter of the probability of repayments is kept at $a=0.124$.

The first panel of Table 2 shows how the benchmark estimates of NDLs change when default risk is introduced. These benchmark estimates take the same growth rates and minimum levels of public revenues and outlays as in the benchmark scenario of Table 1 . The resulting NDLs are significantly smaller (by 17 to 26 percentage points of GDP) than those in the benchmark case without default risk. Note that this sharp decline of the NDLs occurs despite the fact that the risk-free rate at 2.36 percent is about half the long-run real interest rate used in the benchmark scenario of Table 1. The repayment probabilities at 96 percent and the default risk premia around 4.35 percent are similar across countries. The NDLs in this case ensure that governments would be able to repay even during a fiscal crisis, but they still may choose to default on debt ratios about 0.33 with 4 percent probability.

The second panel of Table 2 shows how NDLs change in the growth slowdown scenario (which is perhaps more relevant since the data used to calibrate the risk free rate and the repayment probability function are for the 19901-2002 period). Again, relative to the growth slowdown scenario of Table 1, we are lowering the risk-free rate from 5 to 2.36 percent and introducing time-varying default risk. To isolate the contribution of the latter, the third panel of Table 2 shows the NDLs obtained using the growth rates of the

\footnotetext{
${ }^{3}$ Note that with default risk, the constant rate of interest in the denominator of the formula for the NDL is replaced with the interest rate including default risk defined in equation (7). Since this interest rate depends on the level of debt, the NDL is now the solution to a non-linear equation.
} 
growth slowdown scenario but assuming that there is no default risk so that countries can borrow at the 2.36 percent risk free rate. Since this rate is about half the one used in Table 1, we obtain very high NDLs (ranging from 73 to 152 percent of GDP).

Two comparisons are interesting to make using the second and third panels of Table 2. First, the fact that the NDLs of the growth slowdown scenario in Table 1 (ranging from 30 to 45 percent of GDP) are much smaller than those of the no-defaultrisk case in panel 3 of Table 2, shows that our strategy of setting a long-run real interest rate of 5 percent as a proxy for default risk in the estimates of Table 1 was not a bad approximation. Second, the calculations of NDLs of the second and third panel differ only because the second incorporates the time-varying default risk premium (i.e., both have the same risk-free rate of 2.36 percent). Since the NDLs without time-varying default risk are 3 to 5 times larger than those with default risk, this comparison shows that default risk has major implications for estimates of NDLs.

The last panel of Table 2 re-computes the required adjustments in outlays (i.e. the values of $g^{\text {min }}$ ) needed to support the observed maximum debt ratios of each country in the 1990-2002 sample as NDLs taking into account time-varying default risk. The adjustments in outlays are significantly larger than those reported in Table 1. Measured in standard deviations, the required adjustment in outlays exceeds the two-standard deviation threshold for all countries and it is larger for Mexico than for the other countries. Measured in terms of percentage points of GDP, the adjustments rank from 9.4 and 6 percentage points for Brazil and Colombia respectively to about 7 percentage points for Costa Rica and Mexico. This ranking suggests again that the debt positions of 
Brazil and Colombia are more difficult to reconcile with fiscal solvency considerations than those of Costa Rica and Mexico.

Figure 4 illustrates the implications of default risk for the dynamics of public debt reflected in the measures of time to hit a fiscal crisis. The average time to hit a fiscal crisis is generally lower once the fact that the default risk premium rises with the level of debt is considered. Moreover, default risk produces debt dynamics that hit NDLs more often. This can be seen in the plots for Costa Rica and Mexico. In Costa Rica's plot, for example, an initial debt ratio of 40 percent produced at least some stochastic simulations in the sampling of 1000 runs in which the debt vanished when we use a fixed interest rate. With default risk, however, all 1000 stochastic simulations eventually hit the NDL and on average it takes about 9 years for the economy to hit a fiscal crisis.

\section{Conclusions, Caveats \& Extensions}

This application of the basic version of the MO model to the cases of Brazil, Colombia, Costa Rica and Mexico shows that, with the exception of Costa Rica, public debt ratios are already close to the natural debt limits that the governments of these countries should respect if they wish to preserve smooth access to debt markets, and protect the credibility of their perceived commitment to be able to repay their debts. This is the result assuming a relatively optimistic scenario in which the growth slowdown of the last two decades is reversed to recover the average per-capita growth rates observed between 1961 and 2000, and the real interest rate remains at a relatively low level of 5 percent. This baseline scenario is also optimistic in that it requires credible commitments to large cuts in government outlays which recent experience indicates are a lowprobability event (in terms of a coefficient of adjustment defined in units of standard 
deviations relative to the mean of the ratio of outlays to GDP). Considering less optimistic scenarios in which growth continues at the low trend of the last two decades or the real interest rate increases to 8 percent, current debt ratios would exceed NDLs even with the same tough stance to cut outlays in a state of fiscal crisis assumed in the benchmark scenario.

The model predicts that the long-run dynamics of the public debt ratio are undetermined (or more precisely that there is no unique, invariant limiting distribution for the debt output ratio). This result needs to be considered carefully. On one hand, the result does not require very strong assumptions: stochastic revenue, relatively inflexible outlays and some limit to debt market access (whether an NDL or some an ad-hoc debt limit). Also, the same outcome would result if we take outlays as given and consider instead arguments for tax smoothing as in Barro (1979). If these are the maintained assumptions of fiscal solvency analysis, the estimates of time to a fiscal crisis and the stochastic simulations of debt ratios shown in Figures 2-4, together with the natural debt limits, summarize all relevant information for assessing whether observed public debt dynamics are sustainable. In addition, we would need to worry about how this nonstationarity property affects other statistical methods of debt sustainability analysis that rely on the existence of a well-defined long-run distribution of debt.

On the other hand, we may question the validity of the assumptions that led to the result of an indeterminate long-run distribution of debt. In Mendoza and Oviedo (2004) we propose a setup in which government chooses its outlays optimally instead of setting ad-hoc rules. In particular, we assume that government outlays yield utility to the private sector, with the added feature of a Stone-Geary-like utility function that sets minimum 
levels of government expenditures. We preserve the spirit of the "tormented insurer's" problem by keeping the assumption that the government aims to maximize its contribution to private utility given the randomness of fiscal revenue and the fact that it can only issue non-state-contingent debt. In this setup, the government has a precautionary-savings motive that yields a unique, invariant limiting distribution of public debt (resulting from the trade off between the need to self-insure against the risk of persistent revenue shocks and the desire to smooth government outlays). The role of the NDL is made clearer because the desire to respect it emerges from the fact that otherwise the government is exposed to the risk of experiencing states in which its outlays can be very low, and the government is very averse to these states because of the constantrelative-risk-aversion nature of the utility function of public expenditures.

Most of the analysis was conducted giving a limited role to default risk (by simply setting a long-run, time-invariant real interest rate with a premium above the risk-free rate). This was done following the approach of the MO model to provide a forwardlooking tool to design fiscal programs with the explicit intention of preserving the government's ability to fulfill its financial obligations. However, default risk is an important feature of emerging markets of sovereign debt, and hence it is worth adding it to the analysis of debt sustainability.

We introduced default risk by adopting an exogenous, exponential probability of repayment that varies with the level of debt. We assumed that lenders are risk neutral and hence are willing to take default risk by lending at a rate that incorporates the premium that equates the expected return of risky lending with the risk-free interest rate. The risk premium function was calibrated to match observed debt ratios and EMBI+ 
spreads on sovereign debt. Introducing this change into the basic version of the M-O model produces smaller debt limits and speeds up the dynamics that lead to states of fiscal crisis in which NDLs are reached. NDLs that completely ignore default risk support dynamic paths of sustainable debt with much higher debt ratios than those obtained when default risk is introduced. However, since the basic M-O model approximated the long-run component of default risk by adding a constant premium above the risk-free interest rate, it yields results for debt dynamics that are a much closer approximation to those produced by the model with time-varying default risk than those of a model that ignores default risk completely.

The application of the MO model undertaken in this paper did not consider two other important elements of the dynamics of public debt in emerging economies: the endogeneity of the tax bases and fiscal policy choices and the role of financial frictions like liability dollarization. The endogeneity of the tax bases can be incorporated into the structure of the MO model. This requires introducing the decisions of the private sector with regard to the variables that determine the allocations and prices that conform tax bases (such as labor supply, consumption, the current account and capital accumulation). Similarly, liability dollarization can be introduced by modifying the model to incorporate tradable and nontradable goods. The dynamic stochastic general equilibrium model studied in Mendoza and Oviedo (2004) tries to make progress in these two directions. 


\section{References}

Aiyagari, S. Rao (1994), "Uninsured idiosyncratic risk and aggregate saving," Quarterly Journal of Economics, 109(3):659-684.

Arellano, Cristina (2004), "Default Risk, the Real Exchange Rate and Income Fluctuations in Emerging Economies", mimeo, Duke University.

Barnhill Jr., Theodore M. and George Kopits (2003), "Assessing Fiscal Sustainability Under Uncertainty,” IMF Working Paper No. WP/03/79.

Barro, Robert J, (1979), “On the Determination of Public Debt,” Journal of Political Economy.

Blanchard, Olivier J., Jean-Claude Chouraqui, Robert P. Hagemann and Nicola Sartor (1990), "The Sustainability of Fiscal Policy: New Answers to an Old Question," OECD Economic Studies, No. 15, Autumn.

Blanchard, Olivier J., (1990), "Suggestions for a New Set of Fiscal Indicators," OECD Working Paper No. 79, April.

Bohn, Henning, (1998), "The Behavior of U.S. Public Debt and Deficits," Quarterly Journal of Economics, v. 113, August, 949-963.

Buiter, Willem H. (1985), "Guide to Public Sector Debt and Deficits," Economic Policy: An European Forum, Vol. 1., November, 13-79.

Calvo, Guillermo A., Alejandro Izquierdo and Ernesto Talvi (2003), "Sudden Stops, the Real Exchange Rate and Fiscal Sustainability: Argentina's Lessons," mimeo, Research Department, Inter-American Development Bank.

Chalk, Nigel and Richard Hemming (2000), "Assessing Fiscal Sustainability in Theory and Practice,” IMF Working Paper No. WP/00/81.

Eaton, Jonathan, and Mark Gersovitz (1981), "Debt with Potential Repudiation: Theoretical and Empirical Analysis," Review of Economic Studies, v. XLVII, 289-309.

Hamilton, James D. and Marjorie A. Flavin (1986), "On the Limitations of Government Borrowing: A Framework for Empirical Testing," American Economic Review, v. 76, September, 809-819.

International Monetary Fund (2002), “Assessing Sustainability,” SM/02/166.

(2003), "Sustainability-Review of Application and Methodological Refinements," mimeo, Policy Development and Review Department. 
Ljungqvist, Lars and Thomas J. Sargent (2000), Recursive Macroeconomic Theory, MIT Press.

Mendoza, Enrique G. Assaf Razin and Linda L. Tesar (1994), "Effective Tax Rates in Macroeconomics: Cross-Country Estimates of Tax Rates on Factor Incomes and Consumption," Journal of Monetary Economics, December, v. 34:3, 297-323.

Mendoza, Enrique G. and Pedro Marcelo Oviedo (2004), "Fiscal Solvency and Macroeconomic Uncertainty in Emerging Markets: The Tale of the Tormented Insurer," mimeo, Iowa State University.

Reinhart, Carmen, Kenneth S. Rogoff and Miguel A. Savastano (2003), "Debt Intolerance," mimeo, IMF Research Department. 
Table 1. Fiscal Sector Statistics and Natural Debt Limits (in percent of GDP)

\begin{tabular}{|c|c|c|c|c|}
\hline & Brazil 1/ & Colombia 2/ & Costa Rica 2/ & Mexico 3/ \\
\hline \multicolumn{5}{|l|}{ Fiscal sector statistics } \\
\hline Public debt & $1990-2002$ & $1990-2002$ & $1990-2002$ & 1990-2002 \\
\hline average & 40.68 & 33.71 & 49.46 & 45.92 \\
\hline maximum & 56.00 & 50.20 & 53.08 & 54.90 \\
\hline year of maximum & 2002 & 2002 & 1996 & 1998 \\
\hline Public revenue & 1990-2002 & 1990-1999 & $1990-2000$ & 1990-2002 \\
\hline average & 19.28 & 12.64 & 20.28 & 22.96 \\
\hline coeff. of variation & 14.13 & 8.86 & 5.41 & 8.04 \\
\hline two-standard dev. Floor & 13.83 & 10.40 & 18.09 & 19.27 \\
\hline Non-interest outlays & 1991-1998 & 1990-1999 & $1990-2000$ & 1990-2002 \\
\hline average & 19.19 & 12.80 & 18.54 & 19.27 \\
\hline coeff. of variation & 13.76 & 13.55 & 9.98 & 3.96 \\
\hline Implied fiscal adjustment 4/ & 2.55 & 2.30 & 1.16 & 2.02 \\
\hline Implied minimum non-interest outlays & 12.46 & 8.81 & 16.40 & 17.73 \\
\hline \multicolumn{5}{|c|}{$\begin{array}{l}\text { Benchmark Natural Debt Limits } \\
\text { (1961-2000 growth rates, } 5 \text { percent real interest rate) }\end{array}$} \\
\hline Growth rate & 2.55 & 1.86 & 1.83 & 2.20 \\
\hline Natural debt limit & 56.09 & 50.49 & 53.31 & 54.92 \\
\hline Blanchard ratio & 3.52 & -5.29 & 54.80 & 131.54 \\
\hline \multicolumn{5}{|c|}{$\begin{array}{l}\text { Growth Slowdown Scenario } \\
\text { (1981-2000 growth rates, } 5 \text { percent real interest rate, benchmark fiscal adjustment) }\end{array}$} \\
\hline Growth rate & 0.48 & 1.05 & 1.25 & 0.83 \\
\hline Natural debt limit & 30.34 & 40.10 & 45.10 & 36.96 \\
\hline Blanchard ratio & 1.90 & -4.20 & 46.36 & 88.52 \\
\hline \multicolumn{5}{|c|}{$\begin{array}{l}\text { High Real Interest Rate Scenario } \\
\text { (1961-2000 growth rates, } 8 \text { percent real interest rate, benchmark fiscal adjustment) }\end{array}$} \\
\hline Growth rate & 2.55 & 1.86 & 1.83 & 2.20 \\
\hline Natural debt limit & 25.19 & 25.81 & 27.39 & 26.53 \\
\hline Blanchard ratio & 1.58 & -2.70 & 28.16 & 63.55 \\
\hline
\end{tabular}

Note: The source of public debt data is IMF, World Economic Outlook, October 2003. The sources of revenue and non-interest outlays are as noted in country footnotes.

1/ Revenue data from IMF, World Economic Outlook, Oct. 2003., non-interest outlays data derived from data for the Central Government in World Development Indicators.

2/ Revenue and non-interest outlays data for Central Government from World Dev. Indicators. 3/ Revenue and non-interest outlays data from IMF, World Economic Outlook, October, 2003. 4/ Implied fiscal adjustment is the number of standard deviations relative to the mean needed to obtain a benchmark natural debt limit equal to the largest public debt ratio observed in the data. 
Table 2. Natural Debt Limits with Default Risk

\begin{tabular}{lcccc}
\hline & Brazil & Colombia & Costa Rica & Mexico \\
\hline Benchmark NDLs with default risk 1/ & & & & \\
$\quad$ Natural debt limit & 33.28 & 33.18 & 34.14 & 33.88 \\
$\quad$ Probability of repayment & 95.96 & 95.97 & 95.86 & 95.89 \\
$\quad$ Default risk premium & 4.31 & 4.30 & 4.42 & 4.39 \\
& & & & \\
NDLs in the growth slowdown scenario with default risk & 26.12 & 30.38 & 32.12 & 29.12 \\
$\quad$ Natural debt limit & 96.82 & 96.31 & 96.10 & 96.46 \\
$\quad$ Probability of repayment & 3.37 & 3.93 & 4.16 & 3.76 \\
$\quad$ Default risk premium & & & &
\end{tabular}

NDLs in the growth slowdown scenario without default risk and risk free rate of 2.36 percent
Natural debt limit
72.95
121.60
152.30
100.80

Required fiscal adjustment to support observed maximum debt ratios as NDLS 2/

$\begin{array}{lcccc}\text { Natural debt limit } & 56.00 & 50.20 & 53.08 & 54.90 \\ \text { Probability of repayment } & 93.30 & 93.97 & 93.64 & 93.43 \\ \text { Default risk premium } & 7.35 & 6.57 & 6.95 & 7.20 \\ \text { Implied minimum non-interest outlays } & 9.82 & 6.85 & 14.12 & 15.23 \\ \quad \text { relative to average outlays } & -9.37 & -5.95 & -4.42 & -4.04 \\ \quad \text { in number of st. devs. } & 3.55 & 3.43 & 2.39 & 5.30\end{array}$

Notes: Calculations done as described in the text, using a risk free rate of 2.36 percent, which is the 1990-2002 average of the inflation-adjusted 90 -day U.S. T-bill rate, and a curvature parameter for the risk function of $a=0.124$, which was calibrated to match the EMBI+ spread and the debt ratios observed in Mexico in 1998. 1/ Based on the benchmark values of growth rates and minimum revenue and outlays shown in Table 1 2/ Values of minimum outlays required to support maximum debt ratios shown in Table 1 as NDLs in the setting with default risk, using growth rates from the benchmark scenario. 
Figure 1. Total Public Debt as a Share of GDP

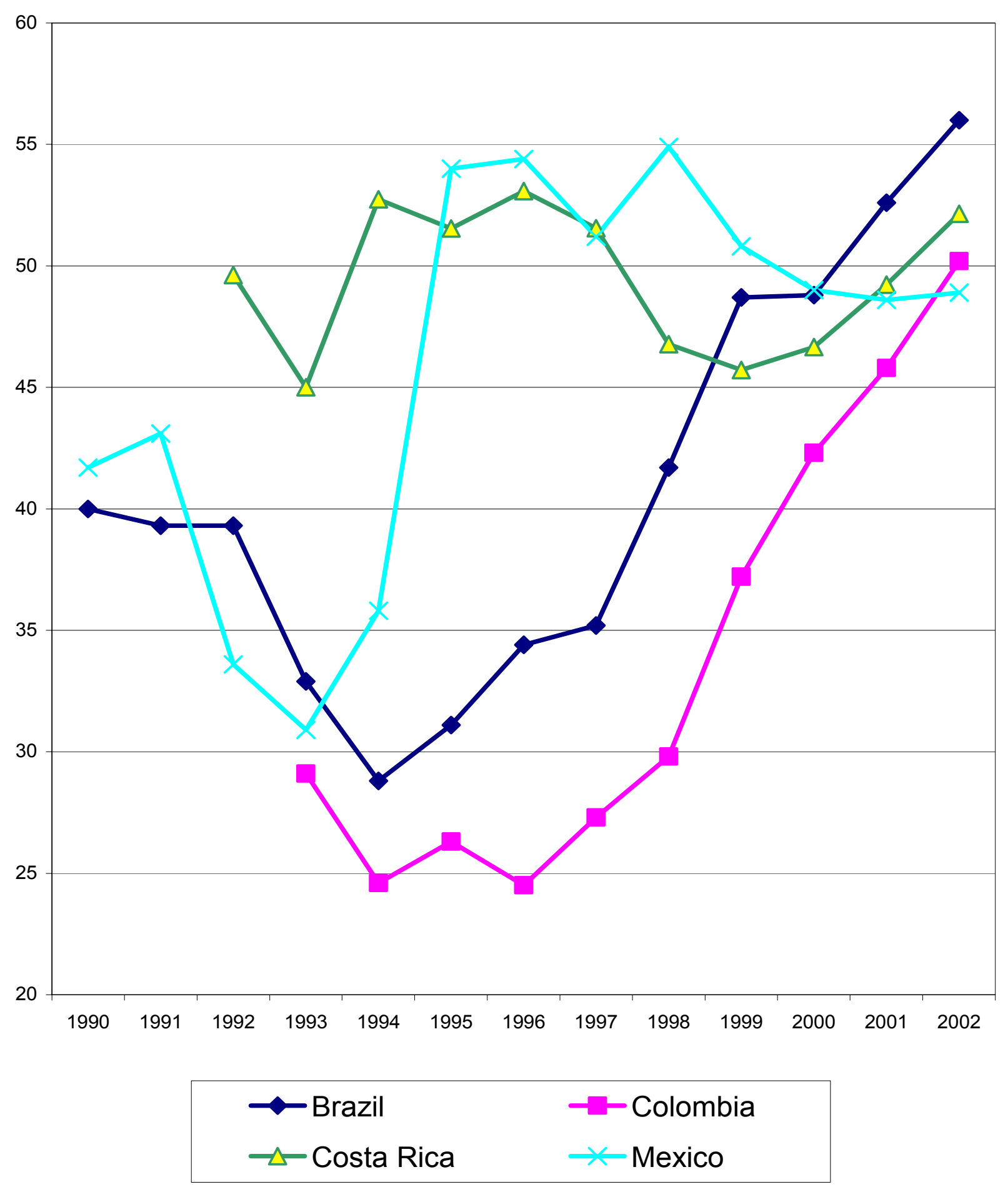


Figure 2. Number of Periods before Hitting a Fiscal Crisis
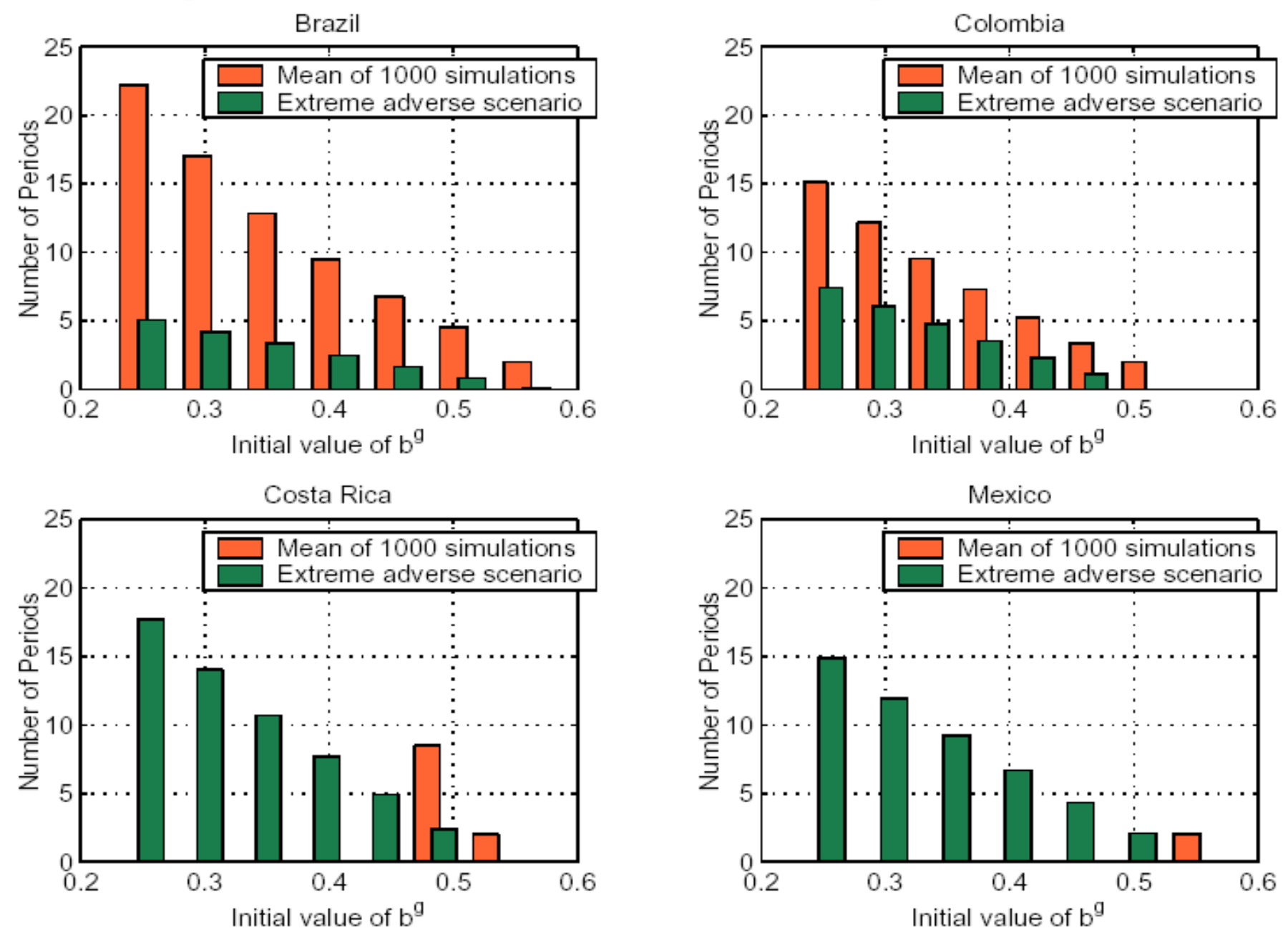
Figure 3. Simulations of Deb-to-GDP in Costa Rica. Starting value $\mathrm{b}_{0}^{\mathrm{g}}=0.35$

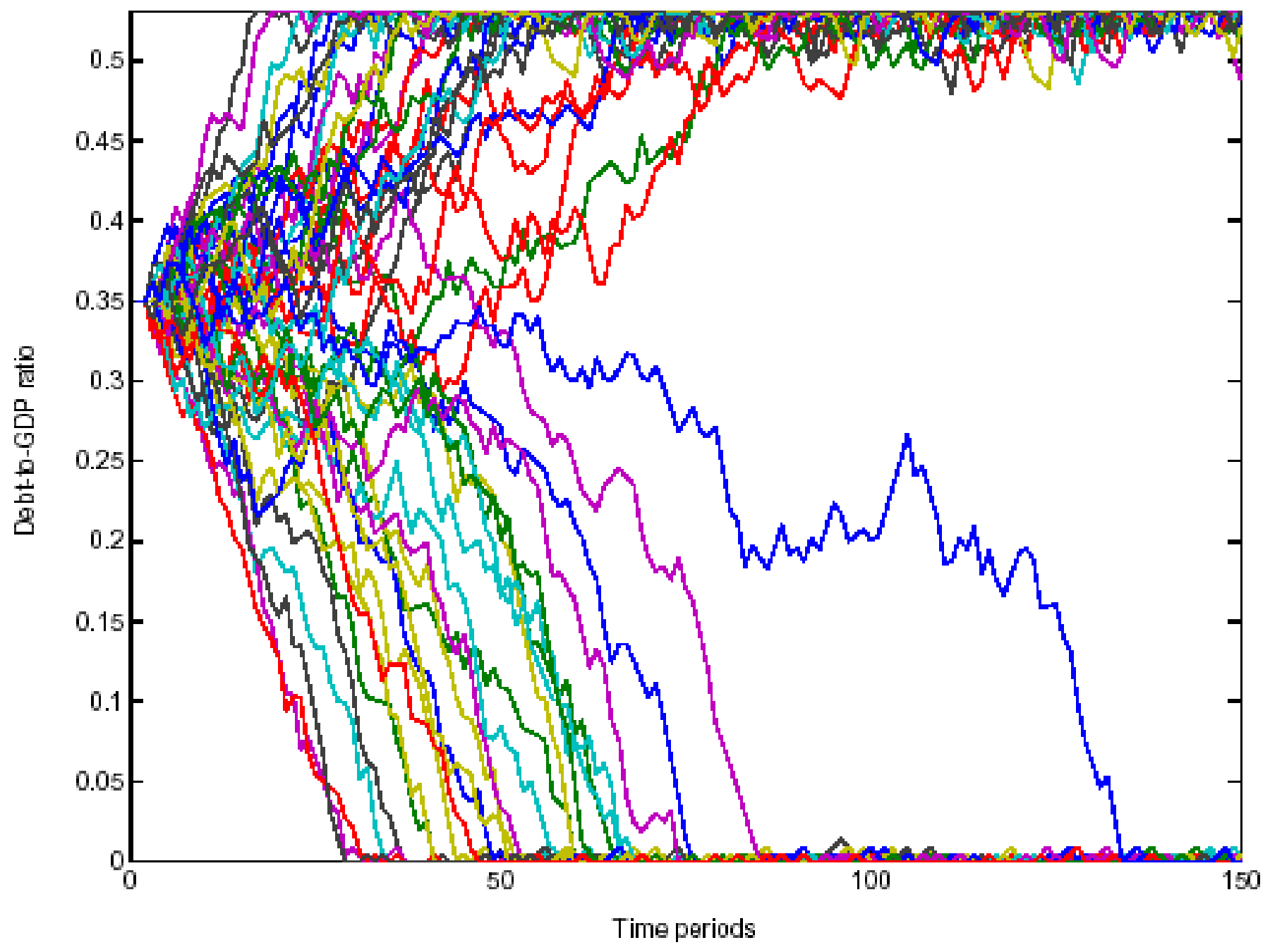


Figure 4. Time to Hit a Fiscal Crisis with and without Default Risk
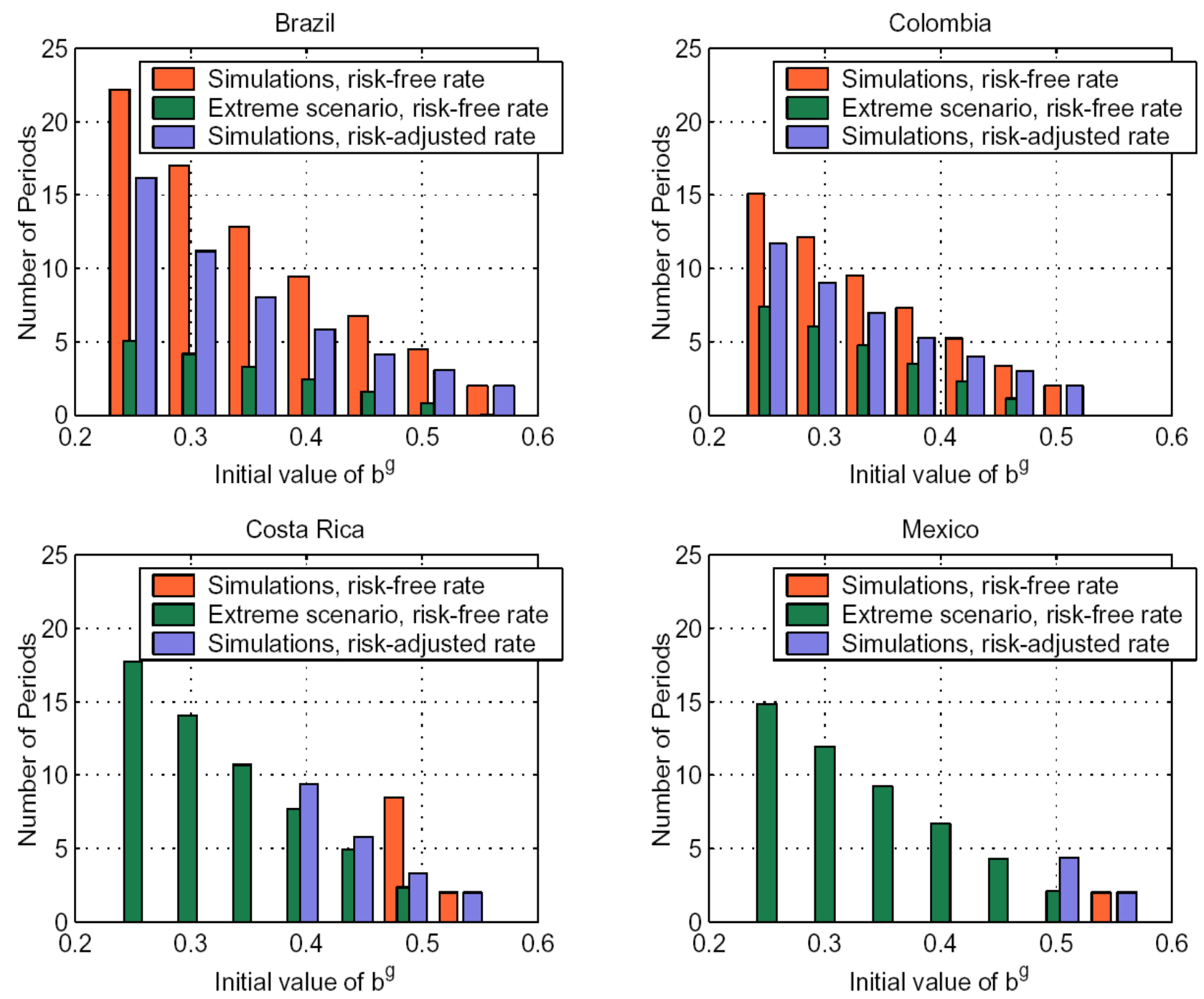